


\title{
Nietzsche: drama y filosofía
}

\section{Nietzsche: drama and philosophy}

\author{
Crescenciano Grave Tirado \\ Universidad Nacional Autónoma de México
}

\section{Resumen}

La obra de Nietzsche continúa interpelándonos. Este ensayo propone una ruta para responder dicha interpelación. En la obra de Nietzsche el pensamiento alcanza a configurar un drama en el sentido de acontecimiento. Este acontecimiento se asume como expresión de la voluntad de poder y se despliega como una crítica de la decadencia y la moral modernas.

Palabras clave: drama, filosofía, decadencia, moral, modernidad.

\begin{abstract}
Nietzsche's work keeps interrogating us. This essay proposes a way to responded that question. In Nietzsche's work the thought sets up a drama in the sense of event. This event assumes itself as an expression of the will of power and spreads out itself as a critique of the modern decadence and morals.
\end{abstract}

Keywords: Drama, Philosophy, Decadence, Morals, Modernity. 
Un filósofo: es un hombre que constantemente vive, ve, oye, sospecha, espera, sueña cosas extraordinarias; alguien al que sus propios pensamientos le golpean como desde arriba y desde abajo, constituyendo su especie particular de acontecimientos y rayos; acaso él mismo sea una tormenta que camina grávida de nuevos rayos; un hombre fatal, rodeado siempre de truenos $y$ gruñidos $y$ aullidos $y$ acontecimientos inquietantes.

NieTzSCHe

R ecreando el problema de la verdad en función de la vida, Nietzsche dedicó su existencia al pensamiento con tal intensidad que su destino terminó componiendo la figura de un drama. ¿Cómo entender esta coincidencia de drama y filosofía? ¿Esta coincidencia es decisiva para acercarse comprensivamente a la trama problemática que despliega su obra? El filólogo Nietzsche se niega a aceptar la traducción de la vieja palabra "drama" como acción: en el drama antiguo la acción estaba supuesta antes del comienzo de modo que quedaba desplazada tras la escena. "El drama antiguo contemplaba grandes escenas patéticas [...] La palabra drama es de origen dorio: y conforme al uso dorio significa «suceso» o «historia», ambas palabras en sentido hierático" (Nietzsche, 2002: 34). Permitiendo contemplar el acaecer de lo monstruoso o terrible -deinon- como pathos sagrado, el drama antiguo mostraba el devenir y el conflicto por el que el fondo mismo de la existencia se dilapidaba mediante los individuos excepcionales. Siguiendo esta indicación es posible ver la trayectoria de la vida y obra de Nietzsche como un drama filosófico: un acontecimiento en el cual se contempla el pathos de una voluntad de conocimiento transida por la interrogante sobre las posibilidades del pensamiento y el lengua- 
je para expresar el devenir azaroso de la existencia cuya necesidad rehúsa todo sentido en sí.

Este drama, quizá, alcanza su mayor intensidad y altura en las obras posteriores al evangelio dionisíaco Así habló Zaratustra. Antes de penetrar en las siniestras sombras de la locura, Nietzsche escribió y publicó Más allá del bien y del mal, La genealogía de la moral, Crepuisculo de los ídolos, El Anticristo, El caso Wagner, Nietzsche contra Wagner y Ecce homo: cada uno de estos libros pone en obra diferentes elementos que, entrelazando distintas fuerzas expresivas, conforman un drama filosófico cuya historia resquebraja los cimientos de la tradición metafísica y, sobre todo, se alza como un suceso intempestivo que, aun dejado en silencio por las corrientes de la modernidad dominante, continúa con su potencia perturbadora todavía capaz de ayudarnos a leer las señales que, después de la muerte de Dios, designan nuestra irreversible caída. El drama filosófico de Nietzsche es una estrella en ruinas que, sin hundirse en el ocaso, continúa emitiendo una luz que insta a confrontarnos con nuestro mundo y con nosotros mismos.

La obra de Nietzsche -como todo pensamiento que, enfrentándose a su época, da cuenta de ella- es constitutiva de la modernidad disonante. Alejado de la pretensión de sistematizar la mirada del mundo moderno sobre sí mismo, su escritura es testimonio de las hendiduras que la visión dominante de la modernidad no ha podido suturar. Evitando el trabado adhesivo de sus distintas proposiciones a una identidad de principio única, así como impidiendo la desbandada de su pensamiento en meras opiniones, la obra de Nietzsche ocurre como filosofía en la que el mundo moderno se confronta consigo mismo desde la voluntad intempestiva y disonante de pensarlo queriendo ver más de lo que la visión dominante 
de ese mismo mundo pone como sus fundamentos. ${ }^{1}$ La obra de Nietzsche nos mira lanzando una gran conmoción interrogativa sobre nosotros. Al responder a esta mirada se alumbra el peligro de nuestro desamparo: "cuando un gran pensador viene a la tierra, todo corre peligro. Es como si en una gran ciudad se hubiera desatado un incendio y nadie supiese qué está a salvo ni dónde acaba el fuego. El amor a la verdad es algo terrible y posesivo; es un incendio: los hombres llamados a buscar poder deben saber qué manantial de heroísmo brota de él" (Nietzsche, 2002: 105). Nietzsche combatió los abismos que advenían a su consciencia con el demonio de la ironía.

Nietzsche se sabe perteneciente a su propia época y sabe también que, en tanto filósofo intempestivo, se exige contender contra ella. "Vencer en sí mismo a su tiempo, venir a ser "intemporal»" (Nietzsche, 2002: 21). El producto más siniestro de la modernidad, aquel por el cual ésta no puede ir más allá de sí misma, es la decadencia. En tanto la modernidad insiste en sobrepasar a su decadencia luchando contra ella desde la pretensión de "mejorar" a la naturaleza, la historia y el hombre mismo con las herramientas de la racionalidad instrumental, la decadencia misma progresa. La racionalidad técnica, la economía basada en el cálculo y la utilidad, la moral con pretensiones de valor absoluto combaten la decadencia sin salir de ella (Cfr. Nietzsche, 1979: 43): su solución no pasa de ser una expresión modificada de la decadencia moderna.

Hijo de su propio tiempo, Nietzsche asume a la filosofía como una rebelión contra las fuerzas dominantes de su época. La ironía:

1 "Desde que en el seno de la Grecia clásica, Platón comenzara a desarrollar el denominado pensamiento dialéctico, han sido muy pocos los filósofos capaces de proponer un trabajo que, siendo tan heterogéneo como el de Friedrich Nietzsche, haya mantenido, sin embargo, una sólida consistencia interna; una obra que sin dejarse arrastrar hacia el caos o el sinsentido evitase, al mismo tiempo, generar una visión omnicomprensiva que la clausurase como un todo" (Fuentes Feo, 2007: 9). 
ese exceso de conciencia sobre sí lo impulsa a confrontarse con la modernidad decadente dentro de la cual él es el viajero que no encuentra el camino a casa - porque la misma modernidad condena la existencia pensante al desarraigo- sino que se extravía en el laberinto de contradicciones al que su desbordada inteligencia lo destina. En este laberinto, Nietzsche no sólo combate al Minotauro; él es también el monstruo que, luchando contra sí mismo, se regala la altura y la profundidad de su mirada.

Nietzsche, en El caso Wagner, es enfático respecto a la imbricación de la decadencia y la moral modernas: al ahondar en la primera, la segunda aparece como su versión más peligrosa. El problema del bien y del mal y su trasunto moral en la modernidad es, como resultado de su peculiar genealogía y consolidación histórica, un destacado signo de decadencia: la moral esconde y, a la vez, refiere una forma de vida cansada y empobrecida. Modernidad, decadencia y moral conforman una estructura solapada cuya expresión se concentra en la última, de modo que la moral se convierte en un signo cuya interpretación penetra en la perspectiva de la vida que se manifiesta o emboza en sus virtudes y valores. La moral moderna es signo de una vida que, desde la negación y el odio, prohíbe todo aquello que "sólo se justifica por la plenitud, por la riqueza excesiva de fuerzas" (Nietzsche, 2002: 57). La confrontación crítica con la moral escenifica el conflicto del pensador consigo mismo y con su mundo. Actor y escenario de este conflicto, Nietzsche cultiva el pathos de la distancia respecto a su propia época y asume "una monstruosa lejanía" para contemplar "el hecho humano... allá abajo" (Nietzsche, 2002: 22). Y, no obstante, este desasimiento es el que le permite componer el drama de su pensamiento donde acontece la perturbación de ciertos fundamentos de la modernidad.

Las distintas singladuras de la travesía de Nietzsche le posibilitaron adquirir la experiencia de la soledad desde donde acometió su 
tarea: el pensador requiere "una enajenación, frialdad y desencanto profundos respecto a todo lo que es del tiempo, todo lo que es de su tiempo" (Nietzsche, 2002: 21-22). El pensador -el filósofo tal y como Nietzsche recrea esta figura- se vuelve un ser extraño en el mundo y éste, visto desde el suceso que es el pensamiento, aparece fuera de sus ejes; el pensamiento que responde a las consecuencias de la muerte de Dios - muerte causada por la propia modernidad filosófica -constata que este acontecimiento vuelve tierra baldía al mundo -el hombre mismo seca las fuentes trascendentes del sentido $-y$, a la vez, fustiga las sombras que, tras la desaparición de Dios, han pretendido ocupar su lugar: el sujeto como centro trascendental desde donde a priori se posibilitan el conocimiento y la moral universal, la naturaleza reflexionada como un todo unido a un principio -mecánico, orgánico o teleológico- y la historia como un proceso designado por el perfeccionamiento progresivo. Las sombras de Dios combaten la decadencia pero, sin fuerzas para abandonarla, se convierten en expresiones distintas de ella.

La modernidad -autodefinida como la época que consuma la centralidad y el dominio del sujeto racional en el mundo- no sale de la decadencia moral en tanto en ella imperan virtudes y valores sometidos al rasero único de la utilidad. La modernidad avizora y, a la vez, obstaculiza la "afirmación y enaltecimiento que la vida se concede” desde su auge (Cfr. Nietzsche, 2002: 57-58) mostrándose como una época escindida entre el sí que da plenitud y transfigura a las cosas y el no que las empobrece y llena de oprobio. Las dos ópticas que se derivan de esta contraposición son necesarias para el mundo moderno cuya escisión penetra en los mismos individuos. "El hombre moderno representa [...] una contradicción de valores, se sienta entre dos sillas, dice sí y no de una sola vez [...] Pero todos, contra nuestra voluntad, contra nuestro conocimiento, tenemos metidos en la carne valores, palabras, fórmulas y morales de orígenes opuestos" (Nietzsche, 2002: 59). Diagnosticar 
la génesis de esta enmarañada contradicción de las tendencias de la modernidad es un aspecto decisivo para comprender la crítica de Nietzsche a esta época del mundo y la forma de vida que prevalece en ella.

La genealogía de la moral y la crítica a su versión moderna dominante son tareas que Nietzsche realiza como exploraciones de la hipótesis que plantea que todo es voluntad de poder. Desde esta hipótesis la vida se concibe como "instinto de crecimiento, de duración, de acumulación de fuerzas, de poder" (Nietzsche, 1978: 30), lo cual le permite diagnosticar a la modernidad decadente como una época en donde la voluntad de poder, en su dimensión afirmativa y creadora, se ha visto menguada y, a la vez, desenmascarar la idea lineal de progreso que establece como inexorable la superación de lo anterior por lo posterior. "La humanidad no representa una evolución hacia algo mejor, o más fuerte, o más alto, al modo como hoy se cree eso [...] una evolución posterior no es sin más, por una necesidad cualquiera, una elevación, una intensificación, un fortalecimiento" (Nietzsche, 1978: 29). La hipótesis de la voluntad de poder como fondo disperso en la aparición de todo alberga dentro de sí la siniestra posibilidad de que algunas de sus manifestaciones, alcanzando a posicionarse como dominantes, expresen a esa misma voluntad vuelta contra sí. La historia aparece como un ámbito transido por las fuerzas de la voluntad de poder en donde ésta puede aparecer desbordada en la creación o contenida hasta el empobrecimiento soportado desde su propia negación.

El horizonte de la modernidad decadente se avista desde el nihilismo. Éste, como dice Blanchot, es "un acontecimiento que se cumple en la historia" designado por la supresión del ser en sí de los valores (Cfr. Blanchot, 1996: 245). El acontecimiento del nihilismo, del cual la muerte de Dios no es tanto comienzo como alcance de su momento más alto, es afrontado por Nietzsche desde su voluntad de conocimiento. "Estamos avistando una tierra inex- 
ploradas cuyas fronteras no fueron delimitadas por nadie, un más allá de todas las tierras, de todos los rincones hasta la fecha conocidos, un mundo que rebasa de cosas bellas, extrañas, problemáticas, pavorosas" (Blanchot, 1996: 245). La voluntad de poder y el nihilismo operan de manera concomitante en el pensamiento de Nietzsche: el acontecimiento del nihilismo define un complejo expresivo de la voluntad de poder que sólo puede ser confrontado, intentando superarlo, por nuevas formas de creación y expresión de la misma voluntad de poder. La inmensidad de este proyecto se acota desde la filosofía al asumir ésta como una labor destructiva impulsada por la voluntad de soportar la verdad.

\section{II}

Nietzsche -sobre todo en las últimas escenas del drama de su pensamiento- concibe la tarea de la filosofía como una labor demoledora de aquellos ídolos -ideales- que el hombre ha forjado erigiendo una antítesis entre el fantasma creado en su cerebro y los afectos experimentados en toda su dimensión psicofisiológica. "A la realidad se le ha despojado de su valor, de su sentido, de su veracidad en la medida en que se ha fingido mentirosamente un mundo ideal" (Nietzsche, 1984: 16). La guerra de Nietzsche contra los ideales o ídolos de la tradición metafísica se lleva a cabo con jovialidad (Heiterkeit): con una visión despejada y serena del valor de lo que se está atacando y a lo que se pretende superar a través de la transvaloración (Umwertung). La turbiedad espiritual -a modo de verdades y valores- se ha precipitado en la tradición y su solidez resiste las preguntas que se le hacen con el martillo: sus respuestas suenan a hueco y, para el malvado oído del psicólogo Nietzsche, ese sonido vacío es el que le permite escuchar "cabalmente algo que quería permanecer en silencio" (Nietzsche, 1979: 28). Al quebrarla y abrirla con sus preguntas, el filósofo puede oír y 
ver más de lo que, embrollada en sus propios ídolos, la dura coraza del ideal permitía. En la tarea de la transvaloración de los valores se vuelve imprescindible "auscultar a los ídolos" (Nietzsche, 1979: 28) y diagnosticarlos desde la veracidad que asienta a la necesidad que ellos ocultan.

Derrumbar ídolos es la tarea de una mirada penetrante y sin contemplaciones que rasga los velos ideales con que se ha cubierto la realidad y, al mismo tiempo, destraba nuevas posibilidades para que la realidad y el hombre mismo invistan a la verdad. ¿Qué es aquí la verdad? ¿La verdad puede ser aprehendida por el pensamiento y, apofánticamente, trasladarla a los conceptos que la filosofía crea? ¿Qué idea de filosofía se juega aquí poniéndose en obra? La filosofía idólatra ha edificado un mundo de verdad cuyo valor no es sólo epistemológico sino, sobre todo, metafísico y moral. Construido sobre conceptos y sostenido sólo en conceptos, el mundo verdadero se ofrece como idea de una realidad en sí para acceder a la cual es necesario sacrificar en la vida y en el pensamiento todo aquello que no corresponda a la identidad y consistencia del ideal. Esta edificación -necesaria para que cierta forma de vida encuentre su justificación- ha consumado su poder como dominio y aparece como un coto cerrado que prohíbe aventurarse por lo que está tras él. La filosofía de Nietzsche asesta golpes a las muros de ese coto lo suficientemente fuertes hasta infringirle hendiduras por donde poder buscar lo extraño y problemático de la existencia para pensar desde la experiencia "de todo lo proscrito hasta ahora por la moral” (Nietzsche, 1984: 16). La filosofía es una aventura de vida y pensamiento: una experiencia. La propia existencia es la que se experimenta en la filosofía, porque ésta es pensamiento que se hunde en la vida de la voluntad de poder asintiendo la excepcionalidad caudalosa de su despliegue conflictivo. Socavando la cimentación ideal del mundo verdadero en sí mismo, el pensamiento que desciende al fondo de la vida emerge de éste 
trayendo consigo las verdades duras y terribles de la voluntad de poder; verdades que, no obstante, permiten soportar todavía a la vida. “Cuánta verdad soporta, cuánta verdad osa un espíritu?, esto se fue convirtiendo cada vez más, para mí, en la auténtica unidad de medida" (Nietzsche, 1984: 17). Pensada y creada en función de la vida, la verdad se vuelve existencialmente más vasta.

La vida como voluntad de poder es también la que se rehúye; la que, negando su presencia terrible, aparece cubierta con los velos del ideal. Petrificado como moral, el ideal es el ídolo ante el cual el pensamiento domesticado se postra y, alimentado por la tiranía que todo presunto ideal supone, prohíbe internarse por los senderos extraños de la existencia. En su vivida exploración consciente de éstos, Nietzsche dilata el ámbito de expresión de la verdad desde la conformación de un drama ${ }^{2}$ cuya cercana lejanía le permite hacer comparecer y vislumbrar la terrible verdad del fondo de la voluntad de poder. "Nitimur in vetitum [nos lanzamos hacia lo prohibido]: bajo este signo vencerá un día mi filosofía, pues hasta ahora lo único que se ha prohibido siempre, por principio, ha sido la verdad" (Nietzsche, 1984: 17). Violando la prohibición, el pensamiento osado es la dura senda por la cual experiencias poco frecuentes advienen a la consciencia manifestándose en el lenguaje subversivo de una filosofía que, correspondiendo a los impulsos agresivos de la vida, se forma a sí misma como creadora. Lo proscrito accede al lenguaje poniendo al descubierto lo problemático de la verdad que los impulsos creadores de la vida recogidos y alterados en ese mismo pensamiento y lenguaje (logos) -como fragmentos conscientes de la voluntad de poder- expresan y que, en tanto devenir insondable, permanece ausente de todas aquellas

2 "En el drama de la existencia consciente no se conjugan la teoría y la práctica, sino el enigma y la transparencia, el evento y la comprensión" (Sloterdijk, 2009:22). 
formas filosóficas que, dogmáticamente, pretenden aprehenderla en una identidad fija. ${ }^{3}$

La verdad es el despliegue azaroso y necesario de la voluntad de poder que, deviniendo singularidad múltiple y temporal, se escapa de toda formulación definitiva. En su recorrido del territorio accesible de la voluntad de poder - parafraseando a Goethe (Cfr. Eckermann, 2005: 283) - Nietzsche logró simbolizar en algunos destellos el ámbito inaccesible de la misma y, en la constatación del carácter extraño y problemático de lo que rehúye alojarse en el lenguaje, dio forma a su aventura de vida y pensamiento. ${ }^{4}$ Este drama vigoroso de aventurarse por lo inmarcesible cosechando y creando su expresión en un lenguaje de forma fluida y sentido precario y, por tanto, lúcido respecto a su propio carácter de señal de lo inaprehensible, es la experiencia que nos depara la lectura de Nietzsche.

El pensamiento no es una actividad causada por un ente o forma subjetiva que desde sí y por sí se refiera a lo otro. El pensamiento es una pasión y una experiencia en las que el poder que

${ }^{3}$ En este sentido, la filosofía de Nietzsche carece -carencia que proviene de la abundancia de su pensamiento- de un centro o principio por el que la realidad sea concebida como una. Esto explica también la ausencia de un libro que, como obra definitiva, trace y disponga el círculo coherente y sistemático de su filosofía. "En esta obra no hay nada que sea un centro. No hay obra central, ningún Haupwerk. [...] Algo fundamental busca expresarse, un tema idéntico, no idéntico, un pensamiento constante y algo como la llamada de un centro no centrado, de un todo más allá del todo, que no se alcanza nunca, pero que siempre se interroga, y a veces se exige. Ese 'todo' no es un concepto, ni un sistema. La fuerza innegablemente instructiva de este pensamiento consiste en despertarnos a una coherencia que no sea sistemática, sino tal que todo cuanto se emparente con ella parezca acudir de todas partes a fin de parecerse a ella y diferir de ella a la vez" (Blanchot, 1996: 238).

4 "Piénsese de Nietzsche lo que se piense, en un punto tiene que impresionar incluso a sus detractores: fue, con su disposición al riesgo existencial de la verdad, el pensador más audaz de la era moderna” (Sloterdijk, 2009: 50). 
nos constituye se vuelve fecundo. ${ }^{5}$ El pensamiento es un afecto y, en tanto tal, una expresión de la voluntad de poder en la que ésta adviene a la conciencia de sí. No obstante, la expresión consciente no la define, no la identifica, no la aprehende: en el pensamiento la voluntad de poder crece haciendo brotar el abismo de las oposiciones y contradicciones de sus problemas. La fecundidad del poder del pensamiento aumenta preguntando y asintiendo al desgarramiento ontológico e histórico-axiológico que la hipótesis de la voluntad de poder implica. La vida de la voluntad de poder se piensa en la filosofía y desde ésta se derrama como fuerza configuradora de la existencia del filósofo. "Una predilección de la fuerza por problemas para los que hoy nadie tiene valor; el valor de lo prohibido; la predestinación al laberinto. Una experiencia hecha de siete soledades. Oídos nuevos para una música nueva. Ojos nuevos para lo más lejano. Una conciencia nueva para verdades que hasta ahora han permanecido mudas" (Nietzsche, 1978: 25-26). Proviniendo desde abajo, lo instintivo y lo sensible configuran a la conciencia como fuerza creadora que, en la escritura, ensaya la búsqueda de la verdad y experimenta con ella.

\section{III}

En la confrontación de Nietzsche con el escabroso problema de la verdad, no están ausentes una actitud y un tono irónicos. "Suponiendo que la verdad sea una mujer", ésta ha sido cortejada de

${ }^{5}$ En El caso Wagner, Nietzsche recurre a la música para transmitirnos su experiencia del pensamiento. "¿Ha notado alguien que la música libera al espíritu? ¿Que da alas a los pensamientos? ¿Que se vuelve uno tanto más filósofo cuanto más músico se vuelve? El cielo gris de la abstracción, como rasgado por rayos; la luz, lo bastante vívida para alumbrar la entera filigrana de las cosas; los grandes problemas, al alcance de la mano; y el mundo, contemplado como desde lo alto de una montaña. Acabo de definir el pathos filosófico" (Nietzsche, 2002: 24). 
manera equivocada por los filósofos dogmáticos que la han pretendido: la "estremecedora seriedad" y "la torpe insistencia" han sido "medios inhábiles e ineptos" para acercarse a la verdad ( $C f$ r. Nietzsche, 1980: 17). La verdad ha permanecido ajena a los filósofos dogmáticos porque éstos no han respetado el pudor con que aquélla se oculta y no han sabido descifrar las señales en las que se insinúa. Apresando a un fantasma, sustituyendo a las realidades donadas a la interpretación con los ideales a los que se idolatra en la unidad fija e idéntica, la filosofía dogmática ha levantado incondicionales castillos conceptuales que, sin embargo, han sido incapaces de acoger la verdad.

¿Qué lleva al levantamiento de las grandes estructuras conceptuales? Las características comunes de las piedras angulares del dogmatismo filosófico son la superstición y la seducción: "una superstición popular cualquiera procedente de una época inmemorial (como la superstición del alma, la cual en cuanto superstición del sujeto y superstición del yo, aún hoy no ha dejado de causar daño), acaso un juego cualquiera de palabras, una seducción de parte de la gramática o una temeraria generalización de hechos muy reducidos, muy personales, muy humanos, demasiado humanos" (Nietzsche, 1980: 18). Aislar y sustancializar o subjetivizar al alma como yo universal desde el cual se determina la realidad para nosotros, así como confiar en el poder especulativo del lenguaje de la razón para reflejar a la realidad -considerada en sí racional- sin deformarla, son las primeras piedras de las construcciones conceptuales de la filosofía. En estas edificaciones se ha invertido mucho -trabajo, perspicacia, paciencia, espíritu- y sus grandes errores han sido posibles desde esta dedicación de la cual resulta que el mundo y el hombre mismo se han vistos conducidos por ellos. La filosofía dogmática y metafísica ha sido un error, sí, pero un error imprescindible para la vida. Con esto, la crítica de Nietzsche a la 
tradición manifiesta una hondura desde la cual se abre una gama de matices presentes en la historia de la metafísica.

Los matices de la historia de la metafísica occidental se descomponen desde Platón: "el peor, el más duradero y peligroso de todos los errores ha sido hasta ahora un error de dogmáticos, a saber, la invención por Platón del espíritu puro y del bien en sî" (Nietzsche, 1980: 18). Platón significa para Nietzsche el epítome de la metafísica occidental porque en la obra del griego -sin menoscabo de su grandeza- encuentra el gran fruto del modo de pensar antitético -mundo verdadero y mundo aparente- y la semilla de los posteriores desarrollos que este dualismo encontró definiendo a la filosofía y generando el destino de la vida humana en la cultura occidental. Con las fórmulas "espíritu puro" y "bien en sî", Nietzsche localiza el resultado -como error fundamental- de la superstición del alma y de la seducción de la gramática para identificar sus construcciones con la realidad en tanto tal, frente a las cuales, dice, "somos nosotros, cuya tarea es el estar despiertos, los herederos de toda la fuerza que la lucha contra ese error ha desarrollado y hecho crecer" (Nietzsche, 1980: 18). Platón y, sobre todo, el platonismo que ha dominado en la historia occidental son el modelo de toda filosofía que, poniendo a la verdad en la inanidad eterna de la identidad abstraída del tiempo o considerando a la realidad temporal manifestación en movimiento de una verdad esencial cuyo despliegue da lugar a la existencia, niega el perspectivismo, "el cual es condición fundamental de toda vida" (Nietzsche, 1980: 18).

El perspectivismo es condición de la vida porque desde él se entrevé el devenir y la pluralidad en los que aquélla se potencia y se diversifica afirmando sus posibilidades de desbordarse en formas donde se crea y se justifica a sí misma. El perspectivismo desvela la imposibilidad de fijar la identidad de la verdad y, al mismo tiempo, patentiza que ésta puede ser sugerida, evocada, interpretada bajo estrategias de escritura en las que ella misma expresa sus posibi- 
lidades creadoras. El pluralismo es indiscernible de la interpretación: ésta no desvela una verdad oculta; es lectura de procesos en devenir cuya variación de sentidos se crea precisamente en la interpretación, la cual se vuelve más potente cuando en el follaje de sus palabras resuenan distintos significados. Así, hay un pluralismo que es "experiencia del ser múltiple" y otro que dona expansión a ese mismo ser al expresarlo bajo distintas formas lingüísticas (Cfr. Blanchot, 1996: 257). En el perspectivismo se juega el conflicto de las fuerzas de la voluntad de poder y en la interpretación se alumbra la multiplicidad de las direcciones y la pluralidad de las posibilidades de formarse.

El devenir disperso y diverso de la voluntad de poder es el impulso a la interpretación. Todo saber es interpretación. Y Nietzsche, como seńala Jaspers, introduce el elemento diferencial de "la autoconciencia del acto de interpretar" (Jaspers, 1963: 425). La perturbación del saber acotado como interpretación reconoce la precedencia del devenir azaroso y terrible y, a la vez, afirma la necesidad de crear sentidos que, así como mantienen a cierta distancia el abismo tremendo, lo vuelven soportable. La interpretación no disuelve lo inasible; lo avista desde formas de saber que, suponiéndolo, permiten mantenerlo en una lejanía soportable para la vida y, por tanto, ese fondo pavoroso, en su verdad, permanece "en falta" para nosotros (Cfr. Sloterjijk, 2009: 86-87). El saber como interpretación supone lo inconcebible y, a la vez, alejándonos hasta cierto punto de su delirio avasallador, crea un mundo interpretado. "Porque nosotros únicamente podemos querer lo que es aún soportable. Por esta razón, tener conocimiento de la verdad significa también, según Nietzsche, estar siempre situados en una distancia protectora frente a lo insoportable" (Sloterdijk, 2009: 87). La multiplicidad de la interpretación es un evento plural que, proviniendo de lo irreductible a cualquier forma de saber, se monta sobre el acontecimiento del devenir al tiempo que constituye sus posibles sentidos. 
El valor de la verdad para la vida emerge desde las perspectivas de la voluntad de poder constituyendo la existencia del ser humano que transcurre en un mundo trazado y alzado desde la interpretación. "Pero en tal caso, la verdad no será [...] un ente por sí, ni un incondicionado ni algo en absoluto universal. Antes bien, la verdad está indisolublemente unida al ser de lo viviente, dentro de un mundo interpretado por él. Mas este mundo mismo, tal como es para nosotros, está junto a nosotros en el constante proceso temporal del devenir" (Jaspers, 1963: 276). La filosofía constituye este proceso ya como fuerza que pretende fijarlo y dominarlo desde un código que ella misma dicta como tabla de valores (filosofía metafísica y dogmática) o ya como fuerza subversiva que creadoramente aspire a provocar una transvaloración de los valores. Esta provocación se sustenta asumiendo el pensamiento como expresión de la voluntad de poder. Pensar es atenerse a lo que, proviniendo de "una voluntad fundamental de conocimiento" (Nietzsche, 1979: 19), tantea y ensaya en la filosofía el vínculo y el orden de los pensamientos en los cuales esa misma voluntad se pronuncia. La expresión es también el asentimiento del pluralismo de la voluntad; el pensamiento afirma y niega, pregunta y duda; se despliega aclarando o se enrosca en sus sombríos laberintos como otros tantos testimonios de su provenir de una voluntad de poder a la cual él, paradójicamente, no puede aprehender como verdad idéntica a su concepto. El pensar es el alumbramiento de aquello que, transidos por la pluralidad de sus fuerzas en conflicto, nos constituye.

\section{IV}

A la tarea de penetrar en los escondrijos oscuros en que se sustentan las aspiraciones morales de la filosofía metafísica y dogmática junto a la labor de alzar una -otra- filosofía que asumiendo el aspecto creador del poder, se levante pendiendo como un precario 
racimo de lucidez, dedicó Nietzsche las escenas más brillantemente errantes de su drama filosófico. Este drama es la historia de una experiencia que no es aislada ni fortuita; es una necesidad cuya raíz se hunde en la voluntad de poder que encuentra en los pensamientos de la filosofía los documentos de su exigencia.

La exigencia que conduce la tarea de una transvaloración de los valores se concentra "en la pregunta sobre qué origen tienen nuestro bien y nuestro mal" y este origen no se busca "por detrás del mundo" sino en la historia del hombre en el mundo (Cfr. Nietzsche, 1979: 19-20) en el cual ha realizado la interpretación de su existencia y, en esta búsqueda, Nietzsche ausculta esta historia recurriendo a la filosofía que piensa más allá de la antítesis entre lo verdadero y lo aparente. Explorar la historia de la moral, desde una filosofía que pretende ir más allá de las antítesis abstractas, transforma la pregunta por el origen del bien y del mal en una serie de cuestiones problemáticas: “¿en qué condiciones se inventó el hombre esos juicios de valor que son las palabras bueno y malvado?, ¿y qué valor tienen ellos mismos? ¿Han frenado o han estimulado hasta ahora el desarrollo humano? ¿Son un signo de indigencia, de empobrecimiento, de degeneración de la vida? ¿ $\mathrm{O}$, por el contrario, en ellos se manifiestan la plenitud, la fuerza, la voluntad de la vida, su confianza, su futuro?” (Nietzsche, 1979: 20) Nietzsche desplaza el problema de la moral: sin cuestionar su valor, la filosofía se preguntaba por su fundamento -en el hombre (Aristóteles) o en el sujeto racional (Kant)-; ahora, el problema es la moral misma como signo que permite leer e interpretar las perspectivas de la voluntad de poder que se acogen e interpretan en ella.

La pregunta que abre el problema del valor de los valores morales refiere su origen a la indigencia o la plenitud de las perspectivas de vida que se forman y justifican en ellos y este origen requiere de una indagación genealógica que se recorre en dos frentes que la constituyen como un método: primero, el ser humano es el que 
designa ciertos actos suyos y su procedencia como buenos, malos o malvados de modo que éstos, en su formulación lingüística, contienen el valor de su origen; segundo, el origen de los valores morales los vuelve susceptibles de crítica genealógica ${ }^{6}$ para descubrir qué significan; qué perspectiva de vida se crea en ellos y bajo qué interpretación la vida misma se justifica.

El problema central es el valor de los valores morales. Perspectivismo, interpretación y genealogía convergen en la tarea de elaborar una crítica de los valores morales en la cual lo cuestionable sea "el valor mismo de esos valores" (Nietzsche, 1979: 23) de modo que se ponga al descubierto la ambivalencia de la moral misma: la moral como causa o consecuencia, como veneno o medicina, como freno o estímulo; en suma, la moral como máscara. La mirada de Nietzsche en este discernimiento es amplia; ella ausculta y, detectando el problema, golpea sin contemplaciones con el martillo destruyendo las "verdades" más arraigadas y ciertas en la historia de la humanidad; pero reconoce, a la vez, con generosidad, la grandeza presente en ellas desde el asentimiento a su necesidad en tanto expresiones de la voluntad de poder. Develando lo aceptado por considerarse evidente desde los requerimientos de la moral dominante -el bueno (Gut) es superior al malvado (Böse) porque es útil al hombre en tanto tal- Nietzsche introduce la desavenencia. “QQué ocurriría si la verdad fuese lo contrario? ¿Qué ocurriría si en el «bueno» hubiese también un signo de retroceso, y asimismo un peligro, una seducción, un veneno, un narcótico, y que por causa de esto el presente viviese tal vez a costa del futuro? [...] De tal ma-

6 "Genealogía quiere decir a la vez valor del origen y origen de los valores. Genealogía se opone tanto al carácter absoluto de los valores como a su carácter relativo o utilitario. Genealogía significa el elemento diferencial de los valores de los que se desprende su propio valor [...] El elemento diferencial no es crítica del valor de los valores, sin ser también el elemento positivo de una creación" (Deleuze, 1971: 9). 
nera que justamente la moral fuese culpable de que jamás se alcanzasen una potencialidad y una magnificencia sumas, en sí posibles, del tipo hombre? ¿De tal manera que justamente la moral fuese el peligro de los peligros?..." (Nietzsche, 1979: 23-24). El peligro que acecha desde toda moral que se define como única es querer apagar las potencialidades humanas y obstaculizar la diversificación creadora de la voluntad de poder en diferentes formas de vida.

Recorriendo el territorio de la "moral realmente vivida", iluminándolo con la mirada implacable de la genealogía, cuya potencia filosófica se funda en aclarar "toda la larga y difícilmente descifrable escritura jeroglífica del pasado de la moral humana" (Nietzsche, 1979: 24), Nietzsche reconoce que esa historia es, a la vez, el signo desde donde emerge un enigma más complejo - "Nosotros los que conocemos somos desconocidos para nosotros..." (Nietzsche, 1979: 17) - y sobre este ser misterioso y el escenario en el que, errante, ha trazado el origen y el sentido de su deber y de su culpa, de su memoria y de sus deudas, de su conciencia y de su responsabilidad, nos propone una manera prismática de narrar el suceso: una serie de tratados sobre el hombre y su historia moral hilvanados en una escritura filosófica que, emplazándonos, se vuelve surtidora de posibilidades interpretativas. Dentro de éstas se encuentra el atisbo de la complejidad paradójica de la hipótesis ontológica e histórica de la voluntad de poder: la moral que ha prevalecido efectivamente en la historia es una forma de decir sí a la vida mediante actos y valores en los que la vida se justifica a sí misma negando los impulsos que tienden a acrecentarla. La voluntad de poder ha alcanzado mayores cotas de dominio volviéndose contra sí misma y sofocando sus propias fuerzas creadoras. 
Transgrediendo lo prohibido con tal insistencia que pensar lo extraño y lo proscrito se vuelve en él un hábito recurrente, Nietzsche es el filósofo que, excavando en las profundidades ontológicas e históricas de la voluntad de poder, nos hace ver la trenza que, en nosotros mismos, tejen lo terrible del fondo de la voluntad de poder y lo precario de su humana grandeza. Para atisbar este vínculo, componiéndolo en el lenguaje, Nietzsche pone a prueba en su escritura una pluralidad de facultades: distingue, selecciona, jerarquiza y nunca mezcla lo distinto con la pretensión de conciliar todo en la disipación de las diferencias. El vigor de su pensamiento se debe, quizá, a la experiencia de saberse forjar como filósofo formando en el lenguaje la pluralidad poiética de sus tendencias hasta alcanzar un radical y aristocrático estilo de la contradicción. Estas contradicciones se conectan y estimulan unas a otras en la riqueza de la tentativa más que en la seguridad de la certeza, en el ensayo antes que en la doctrina, en la dispersión más que en la cohesión sistemática y, desde la plenitud de la sugerencia, su trabajo y su arte filosóficos nos confrontan.

La confrontación se nos ofrece permitiéndonos contemplar un drama del pensamiento puesto en obra de forma teatral e introduciendo "nuevos medios de expresión que transformaron la filosofía” (Deleuze, 2005: 35). Estos nuevos medios de expresión filosófica -el aforismo y el poema, la narración y el ensayo, la sentencia y el tratado que despliega su propia interpretación del aforismo que lo desencadena- están colmados de aseveraciones muchas veces opuestas cuyo movimiento literario simboliza en sí mismo las contradicciones del todo que, acechado desde fragmentos que cancelan la posibilidad del sistema, rehúye su subordinación a una unidad idéntica. En el estilo de la escritura de Nietzsche (Cfr. Nietzsche, 2002: 35) la palabra no se aísla de la frase, la frase no desborda la página que ilumina su sentido sin disgregarse del todo que justo en los espacios en blanco entre las palabras, las frases y 
los fragmentos compone la tensión y la armonía que lo mantienen como una obra viva. El pensamiento fragmentario -replicando el misterio de la divinidad descuartizada que desde la ebriedad y el éxtasis propicia el vínculo de lo terreno y corpóreo con lo celeste y espiritual-sabe que la totalidad se preserva contradiciéndose hasta el desgarramiento. El estilo literario de la filosofía de Nietzsche expresa una voluntad de conocimiento "que quiere ir a buscar lo verdadero en las profundidades donde lo verdadero no ignora las contradicciones" y, en este mismo impulso, "el todo no unitario" provee la pasión de la búsqueda que no excluye la autocrítica de lo encontrado en anteriores singladuras de su travesía (Cfr. Blanchot, 1996: 238-239). Las distintas peripecias del drama son otros tantos avatares en donde la voluntad de conocimiento se expone y se arriesga ensayando su escritura.

La grandeza del estilo literario de Nietzsche lo convierte en un pensador endemoniadamente complicado. "No conozco ningún otro modo de tratar con tareas grandes que el juego: éste es, como indicio de la grandeza, un presupuesto esencia [...] Mi fórmula para expresar la grandeza en el hombre es amor fati [amor al destino]: el no querer que nada sea distinto, ni en el pasado, ni en el futuro, ni por toda la eternidad. No sólo soportar lo necesario, y menos aún disimularlo -todo idealismo es mendacidad frente a lo necesario- sino amarlo..." (Nietzsche, 1984: 54). Desde el juego de pensar lo necesario sin anular el poder que alberga la posibilidad de enriquecerlo en la diferenciación consigo mismo se vislumbra, iluminada por la pavorosa lucidez del que sabe reír temerariamente con el pensamiento, la conciencia de Nietzsche anegada por la constatación de que todas las formas mediante las cuales se ha pretendido aceptar o resistir el dolor de la existencia transfigurándolo en pequeñas alegrías son un espejo -un mundoen donde el dios del vino se contempla. "Pero el día que podamos decir de todo corazón: «iAdelante! ¡También nuestra vieja moral 
forma parte de la comedia!», habremos descubierto un nuevo enredo y una nueva posibilidad para el drama dionisíaco del «destino del alma»-: ¡y ya él sacará provecho de ello, sobre esto podemos apostar, él, el grande, viejo y eterno autor de la comedia de nuestra existencia!..." (Nietzsche, 1979: 25). Convirtiendo la fatalidad en destino, el drama filosófico de Nietzsche nos lega un enigma cuyo trasfondo no nos condena al desvarío inane sino que, espigando los racimos de lucidez, nos permite introducirnos en él vislumbrando algunos signos para intentar comprender un acaecer pensado de la voluntad de poder que tuvo consciencia, a pesar de lo luminoso de su expresión, de la oscuridad -a veces siniestraque lo envolvió. Desde su profunda soledad, el filósofo Nietzsche nunca estuvo solo: en compañía de su más honda necesidad (al lograr las formas que la expresaban) alcanzó también su más profunda libertad, vivió y compuso un drama del pensamiento que aún acontece sin consumar su comprensión. "Los acontecimientos y pensamientos más grandes -y los pensamientos más grandes son los acontecimientos más grandes- son los que más se tarda en comprender: las generaciones contemporáneas de ellos no tienen la vivencia de tales acontecimientos, -viven al margen de ellos" (Nietzsche, 1980: 247). Acontecimiento constitutivo y decisivo de la constelación disonante de la modernidad, la filosofía de Nietzsche preserva una potencia subversiva cuya reanimación conlleva el riesgo de confrontarnos hasta el extrańamiento con nuestro propio mundo. Esta subversión es radical: la existencia no conoce experiencia más abismal que el pensamiento.

\section{Bibliografía}

Blanchot, Maurice, 1996, El diálogo inconcluso, Pierre de Place (trad.), Caracas, Monte Ávila Editores. 
Deleuze, Gilles, 1971, Nietzsche y la filosofia, Carmen Artal (trad.), Barcelona, Editorial Anagrama.

, 2005, La isla desierta y otros textos. Textos y entrevistas (19531974), José Luis Pardo (trad.), Valencia, Editorial Pre-textos.

Eckermann, Johan Peter, 2005, Conversaciones con Goethe, Rosa Sala Rose (trad.), Barcelona, El Acantilado.

Fuentes Feo, Javier, 2007, Un contexto heredado. Friedrich Nietzsche y el arte del siglo XX, Murcia, CENDEAC.

Jaspers, Karl, 1963, Nietzsche. Introducción a la comprensión de su filosofar, Emilio Estiú (trad.), Buenos Aires, Editorial Sudamericana.

Nietzsche, Friedrich, 1975, Crepúsculo de los idolos, Andrés Sánchez Pascual (trad.), Madrid, Alianza Editorial.

, 1978, El Anticristo, Andrés Sánchez Pascual (trad.), Madrid, Alianza Editorial.

, 1979, La genealogía de la moral, Andrés Sánchez Pascual (trad.), Madrid, Alianza Editorial.

, 1980, Más allá del bien y del mal, Andrés Sánchez Pascual (trad.), Madrid, Alianza Editorial.

, 1984, Ecce homo, Andrés Sánchez Pascual (trad.), Madrid, Alianza Editorial.

, 2002, El caso Wagner. Nietzsche contra Wagner, José Luis Arántegui (trad.), Madrid, Editorial Siruela.

Sloterdijk, Peter, 2009, El pensador en escena. El materialismo de Nietzsche, Germán Cano (trad.), Valencia, Editorial Pre-textos.

Recibido: 6 de julio de 2016 Aceptado: 14 de noviembre de 2016 